\title{
Gestão estratégica do endomarketing: um estudo de caso de geração de vantagem competitiva em academias esportivas*
}

\section{Strategic management of endomarketing: a generation case study of competitive advantage in sports academies}

Fabyola Simonassi ${ }^{1}$ Jéssica Fernandes da Silva ${ }^{2}$
Recebido em: 27/04/2015.

Aprovado em: 30/05/2015.

1 Formada em Administração pela UnB, fez pós-graduação em Planejamento Estratégico, Gestão de Projetos e Marketing, pela UFSC, e Inteligência Competitiva, pela UnB. Fez mestrado em Novas Tecnologias de Comunicação para o Patrimônio Cultural, na Universidade da Lugano, na Suíça. E-mail: bia.simonassi@ gmail.com.

2 Especialista em Gestão da Comunicação nas Organizações pelo Centro Universitário de Brasília (UniCEUB); graduada em Comunicação Social, habilitação em Jornalismo pela Faculdade de Ciências Sociais e Tecnológicas (Facitec/ Estácio de Sá). E-mail: jessica.fernandeva@gmail.com.

\section{Resumo}

Esta pesquisa monográfica investigou, por método exploratório, se duas academias esportivas localizadas no Distrito Federal utilizam o endomarketing como estratégia para gerar vantagem competitiva no mercado. Desde a antiguidade, a sociedade persegue o ideal de perfeição do corpo humano e a beleza, bem como o bem-estar e a saúde. Do surgimento das primeiras academias esportivas, até os modelos atuais de grandes franquias dedicadas a esse segmento, a demanda por seus serviços ainda aumenta. $\mathrm{O}$ Brasil ocupa segundo lugar em crescimento do segmento de academias esportivas no mundo. Por outro lado, esse tipo de empresa apresenta indicadores de gestão de pessoas, de marketing e de comunicação ineficientes e/ou ineficazes. Como resultado da pesquisa, identificou-se que as academias estudadas desconhecem o endomarketing, pois não o praticam de forma sistemática e não exploram adequadamente suas ferramentas. Foi definido o nível de endomarketing em que elas se encontram, bem como sugeridas diretrizes para eventual e futuro programa de endomarketing.

Palavras-chave: Endomarketing. Marketing interno. Pesquisa de clima organizacional. Academia esportiva. Academia de ginástica. Fitness.

\begin{abstract}
This monographic research investigated for exploratory method, if two fitness facilities located in the Distrito Federal (Brazil) use endomarketing as a strategy to generate competitive advantage in the market. Since ancient times, the society pursues the ideal of perfection of the human body and beauty as well as the well-being and health. The emergence of the first gyms to current models of major franchises dedicated to this segment, the demand for their services also increases. Brazil ranks second in growth of fitness segment in the world. On the other hand, this type of company has people management indicators, marketing and communication inefficient and / or ineffective. As a result of the research, it was found that the fitness facilities studied are unaware of the endomarketing, do not do the practice systematically and not adequately explore its tools. It was verified the endomarketing level where they are, and suggested guidelines for a future and possible endomarketing program.
\end{abstract}

Keywords: Endomarketing. Internal marketing. Organizational climate survey. Sports academy. Gym. Fitness. 


\section{Introdução}

O estudo proposto neste artigo foi apresentado ao Centro Universitário de Brasília (UniCEUB/ICPD) como pré-requisito para a obtenção de certificado de especialista em Gestão da Comunicação nas Organizações.

A sociedade contemporânea persegue os ideais de beleza baseada na vaidade estético-corporal, na saúde perfeita e no bem-estar. É senso comum que tais estereótipos são produtos da influência midiática: "as pessoas baseiam o que é belo de acordo com a exibição diante das programações televisivas e comerciais" (BARBOZA; FERNANDES; SILVA, 2011, p. 25).

O aumento da perspectiva de vida (IBGE, 2000; 2002) tem sido associado aos avanços da medicina e da tecnologia. Não raro encontrar referências sobre idosos que foram submetidos a condicionamento físico adequado, o que melhorou suas condições motoras, psicológicas e neurológicas (ANTUNES et al., 2001, p. 27). Estudos também têm alertado a população mundial quanto ao sobrepeso em crianças e adolescentes enquadrados em estilo de vida sedentário associado à nutrição inadequada (BROWNELL, 1994; CONTE et al., 2000)

Para atender às necessidades desse público cada vez mais próximo da promoção de hábitos saudáveis, o mercado se debruçou sobre a criação de academias esportivas e/ ou de ginástica, também chamadas "fitness", que significa "boa condição física", em inglês. Como consequência, esse constitui um dos ramos empresais que mais tem crescido em quantidade de estabelecimentos e lucros (COELHO FILHO, 2000).

Toscano (2001, p. 41) detectou que o segmento de academias, em sua maioria, detém visão periférica e reducionista com acentuada "carência de recursos humanos especializados”. Para Saul Bekin (2006), devem ser algumas das preocupações para empresas: controle de satisfação, o incentivo à qualificação e o bem-estar dentro e fora do trabalho, pois agregam valor ao empreendimento. Uma vez que a propaganda positiva também vem de dentro para fora, nas academias não poderia ser diferente, assegura Bekin. Ele classifica tal atividade como "marketing interno" que baliza intenções motivadoras e beneficiadoras tanto para o empregado como para o empregador e para os clientes.

Com o objetivo de observar se as academias de ginástica praticam consciente e sistematicamente a gestão estratégica de endomarketing, este estudo investigou duas empresas do ramo, localizadas no Distrito Federal, denominadas Academia A e Academia B. A metodologia utilizada aplicou o embasamento teórico prévio ao estudo de caso (YIN, 2001) para averiguar como funciona o endomarketing nas duas academias, com base na perspectiva de funcionários e gestores. Os pontos fortes e pontos fracos do endomarketing praticado nas duas academias foram identificados por meio de pesquisa exploratória quantitativa e qualitativa (LAVILLE; DIONNE, 2008).

A Pesquisa de Clima Organizacional (PESTANA, 2001) foi o método utilizado para analisar a realidade do público interno de cada empresa, por meio da aplicação de questionários com perguntas fechadas e abertas (BEKIN; 2006; p. 88) em duas amostras: gestores e funcionários. Os dados coletados foram tabulados e interpretados em etapas: a) averiguação do nível de abrangência em endomarketing; b) verificação da intersecção de dados entre as amostras; e c) elaboração de diretrizes para programas de endomarketing nas academias A e B.

\section{Revisão bibliográfica}

\subsection{O surgimento e a proliferação das academias}

O condicionamento físico, o culto ao corpo e a busca do ideal de beleza são preocupações humanas desde os primórdios da história. Saba (2012) localizou evidências na Grécia e Roma antigas para "enobrecer o homem e fazê-lo forte e apto" (SABA, 2012, p. 81). Mais tarde, o interesse aumentou graças aos apelos da indústria cosmética (MENEGUELLO, 1996) para aderir aos padrões de beleza dos astros dos filmes de Hollywood (VIGARELLO, 2006), criticado por Theodor Adorno (2009) como parte da 'Indústria Cultural'.

Há, ainda, uma parcela da sociedade que se encaixa na "cultura da corpolatria", termo criado por Estevão e Bagrichevsky (2004) para os praticantes do fisiculturismo (body-building) e pessoas que são adeptas de rotina de sacrifícios para obter um corpo extremamente musculoso.

Em contrapartida, outros autores entendem que a busca pelo aperfeiçoamento estético proporciona, sobretudo, saúde, bem-estar e qualidade de vida. Em consequência, os empresários descobriram um público-alvo para seus investimentos e direcionou-os às academias de musculação (além das clínicas de cirurgia plástica e de estética). (ANTUNES et al., 2001; BARBANTI, 1994; CORBIN; LINDSEY, 1997; AZEVEDO JUNIOR; ARAÚJO; PEREIRA, 2006; SUDO; LUZ, 2007; TOSCANO, 2001). 
A academia consiste em espaço físico e equipado com fins lucrativos, ou seja, empresas, que oferecem programas de exercícios (SABA, 2012), orientações técnicas e avaliações físicas para seus clientes (alunos), sob a supervisão de profissionais formados no curso de nível superior de educação física (TOSCANO, 2001).

O Brasil ocupa o segundo lugar em número absoluto de academias esportivas no cenário mundial, segundo o SEBRAE (2014a), perdendo apenas para os Estados Unidos da América (EUA) e a frente do México. Na América Latina (SETOR, 2013), o Brasil atingiu a liderança.

Já em comparação com os EUA, o Brasil obteve crescimento quanto à quantidade de academias superior ao país norte-americano, $29 \%$, em três anos de análise (RODRIGUES, 2014).

\subsection{O valor e o significado do marketing para as organizações}

Sendo o marketing de relacionamento o precursor do Endomarketing, é preciso entender a procedência da disciplina. A origem da palavra marketing é advinda do latim mercari. Significa transacionar, mercar ou comercializar (COBRA, 1986). No marketing, "os profissionais de negócios adotam o ponto de vista do consumidor e essas decisões são tomadas com base no que o cliente necessita e deseja" (COBRA, 2009, p. 3).

Para Philip Kotler (2007), uma instituição que aplica o marketing é atenta às necessidades dos clientes, promovendo relacionamentos de valor. A função do marketing, afirma o autor, deve abranger os departamentos da empresa em trabalho conjunto direcionado a valores que contribuam para a fidelidade e o encantamento da clientela (LAS CASAS, 2006).

\subsection{0 que é Endomarketing?}

Saul Bekin registrou o termo e conceituou o endomarketing como:

Ações gerenciadas de marketing eticamente dirigidas ao público interno (funcionários) das organizações e empresas focadas no lucro, das organizações não lucrativas e governamentais e do terceiro setor, observando condutas e responsabilidades comunitária e ambiental (2006, p. 47).

O endomarketing consiste em uma disciplina não autônoma, tanto para Inkotte (2000) como para Analisa Brum (1998), visto que reúne características das áreas de marketing de relacionamento, de administração de pessoal, de recursos humanos e de gestão de pessoas.
Os valores organizacionais e as campanhas de marketing precisam atingir primeiramente o público interno para que haja relacionamento duradouro e produtivo, esclarece Brum (1998), ao passo que provoque nos funcionários motivos para se orgulharem de fazer parte dos processos da empresa. A autora afirma que, por meio de técnicas de endomarketing, obtém-se a adesão dos funcionários e colaboradores aos resultados almejados.

Deve-se capacitar primeiramente os colaboradores com informação clara e transparente sobre os processos, procedimentos, metas, campanhas, projetos, serviços e ações, para que, assim, eles sejam capazes de alcançar o desempenho desejado (GRÖNROOS, 1993).

A capacitação dos funcionários constitui elemento primordial no processo de endomarketing, e, para isso, é preciso fidelizar os funcionários como se faz com os clientes, tratando-os com verdadeiros "clientes internos" (BEKIN, 2006). "Antes mesmo de ser um cliente, o funcionário de uma empresa deveria ser considerado um sócio, pois uma organização que visa a lucros é formada pela aliança entre capital e trabalho", destacou Alexandre Inkotte (2000, p. 85).

Apesar da divergência de alguns autores, endomarketing e marketing interno são dois termos que possuem o mesmo significado para Saul Bekin (2006) e Analisa Brum (2010).

\subsubsection{Os Programas de endomarketing}

Os programas de endomarketing são necessários sempre que se identifique como estratégico o comprometimento de toda equipe de colaboradores com os objetivos organizacionais, mas só passam a existir, de fato, tomando-se por base o momento em que a gerência de uma empresa delibera oficialmente inclui-los em seu cotidiano (BEKIN, 2006; BRUM, 2010).

É unanimidade entre os autores Saul Bekin (2006), Analisa Brum (2010), Graziela Graziano (2011) e Alexandre Inkotte (2000) que, para iniciar qualquer programa de endomarketing, é imprescindível realizar, inicialmente, diagnóstico de clima organizacional. Nessa perspectiva é de suma importância o comprometimento de toda equipe de colaboradores: "Quanto mais certeza se tem acerca de um diagnóstico interno, maiores as chances de viabilidade de projetos externos" (BEKIN, 2006, p. 64).

Alves (2002) percebeu também que é no planejamento atento das especificações internas da empresa que se conquistam relações duradouras entre administração, 
funcionários e funções. Uma vez que há o registro e a análise de quais são os fatores de motivação e as formas mais eficientes de gerenciá-las. Requena (2003, p. 25) cita a importância do endomarketing:

[...] o endomarketing é uma arma de comunicação para conquista do corpo de colaboradores (clientes internos) que, uma vez convencidos de que atuam em um negócio seguro, envolver-se-ão ainda mais para fazer dele um empreendimento vitorioso e para propagá-lo para fora de suas fronteiras, levando à conquista do cliente externo.
A pesquisa bibliográfica realizada revelou que não há fórmula única de endomarketing para todo tipo de organização, porém há preceitos gerais que podem e devem ser seguidos por todas as empresas que desejam fazer endomarketing. No quadro 1, pode-se comparar os pontos cruciais dos programas de endomarketing sugeridos por quatro autores.

Quadro 1 - Preceitos gerais para programas de endomarketing para Bekin, Brum, Graziano e Inkotte

\begin{tabular}{|c|c|c|c|}
\hline BEKIN & BRUM & GRAZIANO & INKOTTE \\
\hline $\begin{array}{l}\text { 1. Diagnóstico } \\
\text { 2. Treinamento sob a ótica de educaçãao e } \\
\text { desenvolvimento; } \\
\text { 3. Processos de seleção; } \\
\text { 4. Planos de carreira; } \\
\text { 5. Motivação; } \\
\text { 6. Valorização; } \\
\text { 7. Comprometimento; } \\
\text { 8. Recompensa; } \\
\text { 9. Sistemas de informações e rede de } \\
\text { comunicação interna; } \\
\text { 10. Segmentação do mercado de clientes } \\
\text { internos; } \\
\text { 11. Cenários para novos produtos, serviços e } \\
\text { campanhas publicitárias. }\end{array}$ & $\begin{array}{l}\text { 1. Diagnóstico; } \\
\text { 2. Gestão (objetivos, estratégias, resultados); } \\
\text { 3. Recursos Humanos (benefícios, política } \\
\text { salarial, treinamento); } \\
\text { 4. Mercado e Produto; } \\
\text { 5. Produção (metas e resultados); } \\
\text { 6. Responsabilidade social; } \\
\text { 7. Responsabilidade ambiental; } \\
\text { 8. Celebraçôes; } \\
\text { 9. Participação nos resultados; } \\
\text { 10. Programas de reconhecimento; } \\
\text { 11. Diretrizes e normas internas; } \\
\text { 12. Dia a dia da empresa. }\end{array}$ & $\begin{array}{l}\text { 1. Diagnóstico; } \\
\text { 2. Qualidade de Vida; } \\
\text { 3. Treinamentos de capacitação de } \\
\text { pessoas; } \\
\text { 4. Merchandising de Produtos para os } \\
\text { colaboradores; } \\
\text { 5. Quadro de avisos; } \\
\text { 6. Jornal Interno; } \\
\text { 7. Cultura Organizacional; } \\
\text { 8. Manuais; } \\
\text { 9. Panfletos; } \\
\text { 10. Comportamento Organizacional; } \\
\text { 11. Mudança Organizacional; } \\
\text { 12. Clima Organizacional; }\end{array}$ & $\begin{array}{l}\text { 1. Diagnóstico; } \\
\text { 2. Companhia; } \\
\text { 3. Custos; } \\
\text { 4. Coordenadores; } \\
\text { 5. Comunicação; }\end{array}$ \\
\hline
\end{tabular}

Fonte: Do autor ${ }^{3}$

\subsection{As academias esportivas e o endomarketing}

$\mathrm{O}$ endomarketing tem sido visto cada dia mais presente no discurso dos profissionais de saúde, no cenário internacional, entretanto mais timidamente no território brasileiro (COELHO FILHO, 2000). Com base nisso, foram desenvolvidos pesquisas e estudos de casos a respeito da eficácia do serviço prestado, bem como sobre o endomarketing nas academias.

Coelho Filho (2000) identificou que as grandes academias se concentram em quantidade e não na qualidade de colaboradores, logo, esse quesito contribui para o sucesso ou o fracasso da empresa.

Mocsányi e Bastos (2009), ao investigarem o modelo de gestão das academias esportivas, encontraram cenário de pouca qualificação técnica e valorização de profissionais. Segundo Mendes (2010), esses colaboradores têm de lidar também com baixa remuneração, contratos irregulares e

3 De acordo com autores: Bekin (2006, p. 71); Brum (2010, p. 171); Graziano (2011, p. 124); e Inkotte (2000) condições desfavoráveis para exercício da profissão.

Espírito-Santo e Mourão (2006) constataram que a sobrecarga de trabalho, como também a rotina múltipla, limitam cuidados e asseios com a saúde do próprio profissional:

As megaacademias [sic] justificam o baixo valor de hora/aula com o argumento de que ao entrar na academia o profissional terá possibilidade de conseguir muitos alunos de personal e isso vai fazer com que tenha uma boa renda. O que ocorre na realidade é que eles acabam se sujeitando a essa lógica e isso os deixa na obrigação de trabalhar um número de horas muito pesado para conseguir um salário digno, o que vem interferindo de forma radical no seu estilo de vida (ESPÍRITO-SANTO; MOURÃO, 2006, p. 50-51).

Para cativar os colaboradores (clientes internos) desse tipo de organização, são imprescindíveis: a) a estabilidade e a satisfação dos profissionais envolvidos; b) programas com foco no aprimoramento, seleção de pessoal, treinamento/ desenvolvimento dos funcionários; e c) oferta de benefícios tais como de plano de carreira, entre outros (CHIAVENATO, 2004; PAULA, 1999). 


\section{Apresentação, resultados e interpretação}

O Distrito Federal teve aumento de $238 \%$ no número absoluto de academias esportivas, em sete anos, enquanto, no restante do país, o aumento foi de 188\%, de acordo com estudo recente divulgado pelo Sebrae (DF, 2014). Existe uma academia para cada 4,7 mil habitantes. Ao todo, o DF possui 602 estabelecimentos e 10,6 mil profissionais trabalhando no ramo.

A Academia A é uma empresa de pequeno porte (SEBRAE, 2014b), localizada na região administrativa (RA) do Riacho Fundo I (DF), com 45 colaboradores registrados. Já a Academia $B$ também é uma empresa de pequeno porte (SEBRAE, 2014b) e possui 43 trabalhadores contratados, porém está localizada na região administrativa (RA) de Águas Claras (DF).

\subsection{Resultados e interpretação do estudo de caso}

A seguir, foram demonstradas as respostas dos gestores das academias em contrapartida às dos funcionários em formato de gráficos para elucidar a comparação das pesquisas obtidas.

No Gráfico 1, os funcionários foram separados em três segmentos, conforme o tempo de serviço prestado na academia: o primeiro segmento , 44\%, engloba os funcionários que têm de 1 a 5 anos, o segundo segmento, 24\%, reúne quem tem de 6 a 10 anos de empresa, e o terceiro segmento representa os funcionários com mais de 10 anos de casa, 20\%. Optaram por não responder $12 \%$.

Os funcionários da Academia $\mathrm{A}$, que têm mais tempo de empresa (de 6 a 10 anos) contemplam o maior índice de promoções, com 33\%. Pode-se observar a permanência de profissionais na empresa por longo período como sua característica.

Gráfico 1 - comparativo de tempo de serviço e promoção na Academia A

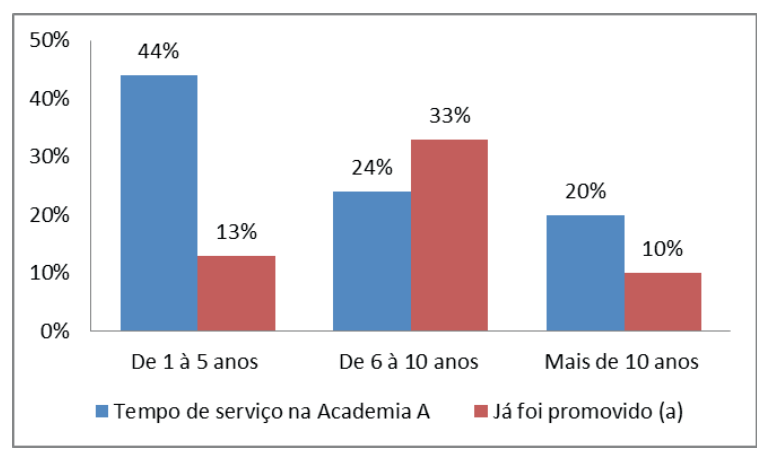

Fonte: Do autor
No Gráfico 2, os funcionários também foram separados em três segmentos, conforme o tempo de serviço prestado na academia: o primeiro segmento, 49\%, engloba os funcionários que têm menos de 1 ano de casa, o segundo segmento, $38 \%$, reúne quem tem de 1 a 5 anos de casa, e o terceiro segmento representa os funcionários com mais de 6 anos de casa, 14\%.

$\mathrm{Na}$ Academia B, os únicos promovidos até o momento são os funcionários com mais de 6 anos de serviços prestados (14\%). Os demais funcionários afirmam que nunca foram promovidos.

Gráfico 2 - comparativo de tempo de serviço e promoção na Academia B

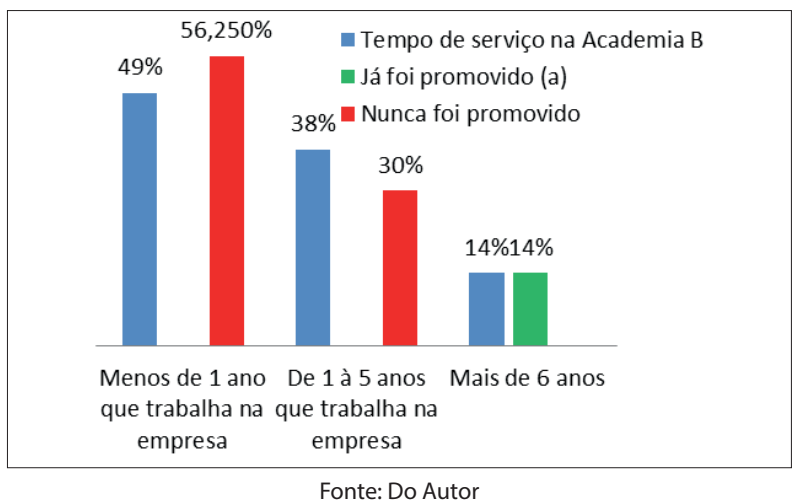

Comparando os dados da academia A e os dados da academia B, nota-se que a primeira tem maior capacidade de retenção de colaboradores do que a segunda, apesar de ambas terem o mesmo porte e número de funcionários equivalentes. Os gráficos 3 e 4 dizem respeito à avaliação dos colaboradores de como a comunicação interna funciona, em ambas as academias.

Podemos observar que, na Academia A (Gráfico 3), $84 \%$ dos entrevistados alega que conhece a missão e os valores da empresa, mas apenas $56 \%$ concorda que as notícias internas são divulgadas aos colaboradores.

Gráfico 3 - gráfico comparativo "Missão e Valores" e "Notícias internas" na Academia A

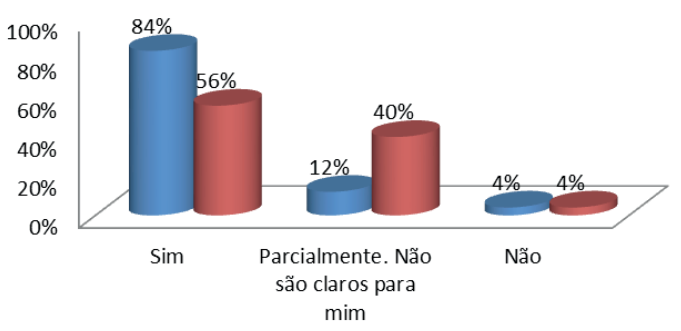

n Conheço a missão e os valores da Academia A

n As notícias internas da Academia A são divulgadas aos colaboradores

Fonte: Do Autor 
$\mathrm{Na}$ Academia B (Gráfico 4), observamos que apenas $54 \%$ dos entrevistados disse que conhece a missão e os valores da empresa, enquanto $60 \%$ mencionaram que as notícias internas são divulgadas aos colaboradores. Contudo, haja vista a citação expressa da missão da Academia B no próprio website, concluímos que os inquiridos não foram tão contagiados como poderiam.

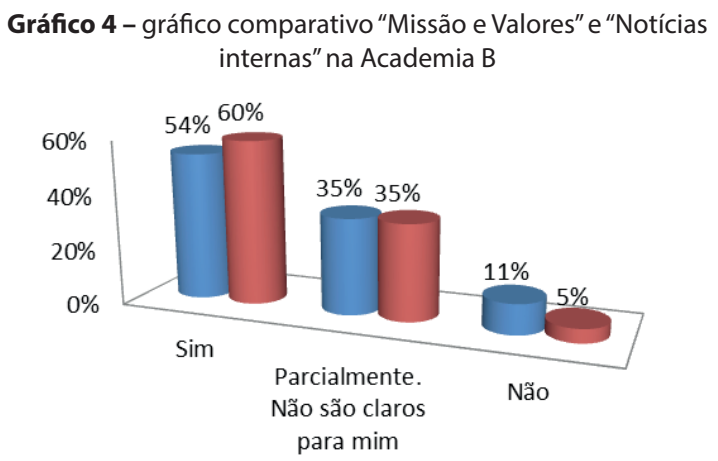

- Conheço a missão e os valores da Academia B

- As notícias internas da Academia B são divulgadas aos colaboradores Fonte: Do Autor

No Gráfico 5, quando os gestores de ambas as academias foram questionados se "a empresa busca de alguma maneira conhecer as necessidades e interesses de seu pessoal", $100 \%$ da Academia A afirmou que sim. Em contrapartida, na Academia B, 70\% dos gestores indicaram que isso acontece parcialmente, e $30 \%$ acha que isso não ocorre na academia.

Gráfico 5 - a empresa busca de alguma maneira conhecer as necessidades e interesses de seu pessoal

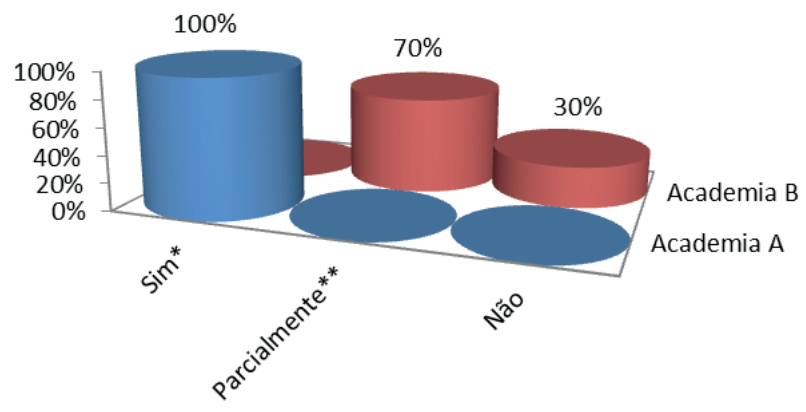

* Sim: é prática corriqueira informal da empresa.

**Parcialmente: Poucos setores e responsáveis praticam.

Fonte: Do Autor

No Gráfico 6, apresentamos a relação dos indicadores na Academia A, como na Academia B, de acordo com a questão "O que você considera ideal que as empresas ofereçam?”
Gráfico 6 - o que o cliente interno considera essencial que as empresas ofereçam: academia A X academia B

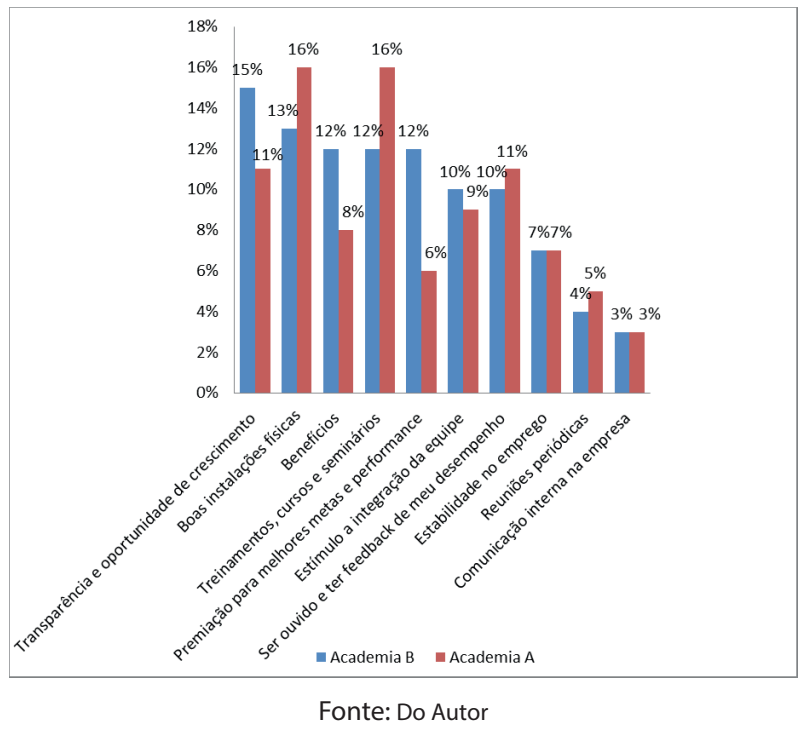

No Quadro 2 constam os quatro indicadores mais votados por ordem de prioridade referente à mesma questão do gráfico 6: na academia A, prevalecem a importância para as boas instalações físicas, bem como os treinamentos, cursos e seminários, ambos empatados com $16 \%$. Na academia B, prevalece o desejo por "transparência e oportunidades de crescimento", com 15\%. As respostas coincidentes foram listadas na terceira coluna "Itens mais votados em comum", logo, à direita, a quarta coluna do quadro diz respeito à somatória de suas porcentagens.

Quadro 2 - O que o cliente interno considera essencial que as empresas ofereçam:

\begin{tabular}{|c|c|c|c|}
\hline Academia A & Academia B & $\begin{array}{c}\text { Itens em comum mais } \\
\text { votados }\end{array}$ & $\%$ \\
\hline $\begin{array}{c}\text { Boas instalações } \\
\text { físicas }\end{array}$ & $\begin{array}{c}\text { Transparência e } \\
\text { oportunidade de } \\
\text { crescimento }\end{array}$ & Boas instalações físicas & $29 \%$ \\
\hline $\begin{array}{c}\text { Treinamentos, } \\
\text { cursose } \\
\text { seminários }\end{array}$ & Boas instalações físicas & $\begin{array}{c}\text { Treinamentos, cursos e } \\
\text { seminários }\end{array}$ & $28 \%$ \\
\hline $\begin{array}{c}\text { Transparência e } \\
\text { oportunidade de } \\
\text { crescimento }\end{array}$ & Benefícios & $\begin{array}{c}\text { Transparência e } \\
\text { oportunidade de } \\
\text { crescimento }\end{array}$ & $26 \%$ \\
\hline $\begin{array}{c}\text { Ser ouvido e } \\
\text { ter feedback de } \\
\text { desempenho }\end{array}$ & $\begin{array}{c}\text { Treinamentos, cursos e } \\
\text { seminários/ Premiação } \\
\text { para melhores metas e } \\
\text { performance pessoal }\end{array}$ & $\begin{array}{c}\text { Estímulo à integração e } \\
\text { espírito positivo da equipe }\end{array}$ & $19 \%$ \\
\hline
\end{tabular}

Fonte: Do Autor

Para completar o estudo proposto neste artigo, os funcionários e os gestores de cada empresa responderam a pergunta "quais pontos positivos desta academia". O Gráfico 7 resume as respostas: 
Gráfico 7 - O que fideliza o cliente interno: comparativo entre amostras dos gestores $x$ funcionários da Academia $A$ x funcionários da Academia B

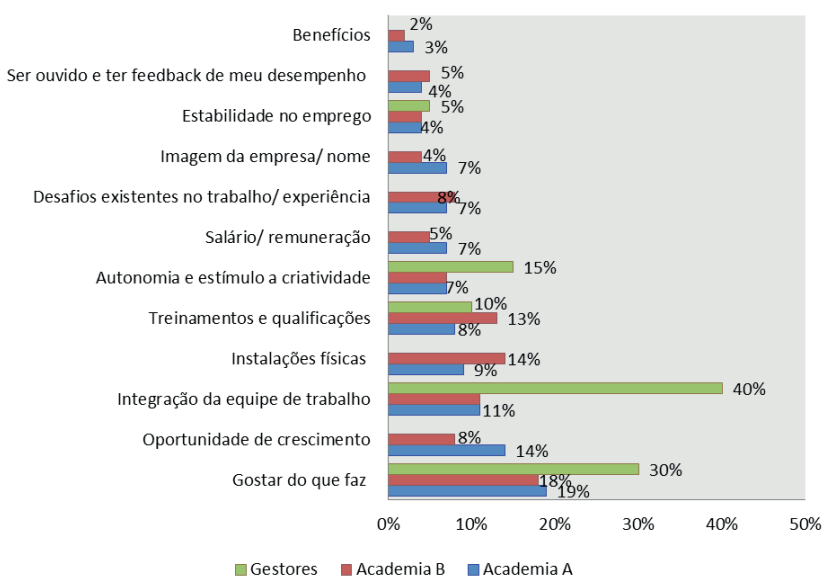

Fonte: Do Autor

O Quadro 3 trata do resumo das informações apresentado no Gráfico 7, em que percebe-se a opinião dos gestores e dos funcionários de ambas as academias sobre o que mais fideliza o cliente interno. Para os gestores de ambas as academias, o principal motivo da fidelização do cliente interno é integração da equipe de trabalho (40\%), gostar do que faz (30\%) ou autonomia e estímulo à criatividade (15\%). Já para os funcionários, o que mais fideliza o cliente interno é gostar do que faz (19\% na academia A e 18\% na academia B), oportunidades de crescimento na academia A (14\%) e instalações físicas na academia B (14\%).

Quadro 3 - o que fideliza o cliente interno: comparativo entre amostras dos gestores $x$ funcionários

\begin{tabular}{|l|l|l|}
\hline $\begin{array}{c}\text { Itens que fidelizam 0 } \\
\text { cliente interno } \\
\text { (para gestores) }\end{array}$ & $\begin{array}{c}\text { Itens essenciais para } \\
\text { fidelização } \\
\text { (para o cliente interno) }\end{array}$ & $\begin{array}{c}\text { Item em comum mais } \\
\text { votado }\end{array}$ \\
\hline $\begin{array}{l}\text { Estímulo à integração e } \\
\text { espírito positivo da equipe }\end{array}$ & $\begin{array}{l}\text { Transparência e } \\
\text { oportunidade de } \\
\text { crescimento }\end{array}$ & Gostar do que faz \\
\hline $\begin{array}{l}\text { Autonomia e estímulo à } \\
\text { criatividade }\end{array}$ & $\begin{array}{l}\text { Treinamentos, cursos e } \\
\text { seminários }\end{array}$ & $\begin{array}{l}\text { Estímulo à integração e } \\
\text { espírito positivo da equipe }\end{array}$ \\
\hline Estabilidade no emprego & Gostar do que faz & \\
\hline Gostar do que faz & $\begin{array}{l}\text { Estímulo à integração e } \\
\text { espírito positivo da equipe }\end{array}$ & \\
\hline
\end{tabular}

Os gestores das duas academias pesquisadas foram levados a refletir sobre o que as academias precisam melhorar para gerar vantagem competitiva, inclusive sendo

4 Elaborado com base nos resultados dos Apêndices A e B induzidos na entrevista a encontrarem pontos positivos na concorrência. No Quadro 4 apresentamos o resumo, por ordem de prioridade.

Quadro 4 - o que as academias precisam melhorar para gerar vantagem competitiva: Academia A x Academia B

\begin{tabular}{|c|}
\hline $\begin{array}{c}0 \text { que as academias precisam melhorar para alavanca } \\
\text { vantagem competitiva? }\end{array}$ \\
\hline $\begin{array}{l}\text { Aperfeiçoamento físico-estrutural } \\
\text { Estrutura física/ estética } \\
\text { Localização } \\
\text { Divulgação/ marketing externo } \\
\text { Relacionamento interno } \\
\text { Comunicação interna }\end{array}$ \\
\hline
\end{tabular}

No Quadro 4, nota-se a dificuldade do gestor de academia em perceber seu colaborador como cliente interno e gerador de vantagem competitiva, pois apenas dois dos pontos tratam da temática: relacionamento interno e comunicação interna, ambos aparecendo por último, na ordem de prioridades.

No Gráfico 8, observamos que 90\% dos gestores desconhecem os conceitos de endomarketing e de cliente interno.

Gráfico 8 - o que é endomarketing e cliente interno: comparativo entre amostras dos gestores da Academia A e da Academia B

\section{O que é Endomarketing e cliente interno}

n Gestores que não souberam responder a Gestores que souberam responder

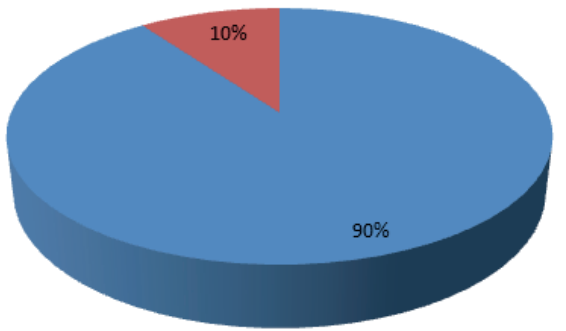

Fonte: Do Autor

\subsection{Níveis de abrangência em endomarketing}

Tomando-se por base os dados coletados no estudo de caso das duas academias, foi possível identificar em que nível de endomarketing cada uma das empresas se encontra, conforme metodologia de Saul Bekin, ilustrada na Figura 1, sendo o terceiro nível o ideal a ser atingido pelas empresas, no qual a cultura do endomarketing está inserida no cotidiano dos departamentos e atividades (BEKIN, 2006). 
Figura 1 - níveis de abrangência (situação) em endomarketing

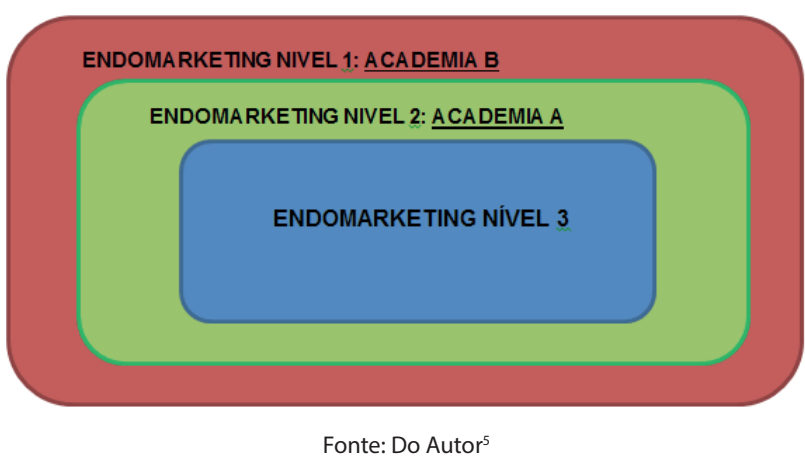

Os dados da pesquisa na Academia A mostraram que existe política de retenção de colaboradores (ver Gráfico 1), que os funcionários se sentem informados sobre a empresa (ver Gráfico 3), e que existe preocupação em saber as necessidades do cliente interno (ver Gráfico 5). Para Saul Bekin, esta empresa se encontra no "segundo nível" de endomarketing, sendo este um nível intermediário. A Academia A precisa, portanto, instaurar processos e procedimentos que mantenham sua cultura própria, de modo a "fazer com que os valores da cultura de serviço possam integrar o cotidiano da empresa" (BEKIN, 2006, p.66).

A Academia B registrou-se mais distanciada das técnicas de gestão de pessoas e estratégias de endomarketing evidenciado baixa adesão de informações internas (demonstrada no Gráfico 4 e também no Gráfico 5), e também o pouco interesse da empresa no cliente interno. Isso posto, essa amostra se encontra no "primeiro nível" de abrangência. O autor lembra que há uma deficiência em se criar uma mentalidade estratégica: "a noção de [endo]marketing deve estar presente em todos os setores, na consciência e na prática de todos" (BEKIN, 2006, p.66).

\subsection{Diretrizes para programa de endomarketing para as Academias A e B}

Com base nos estudos feitos, a título de sugestão, foram elaboradas diretrizes gerais para a elaboração e implementação de programas de endomarketing, no segmento dessas academias esportivas do Distrito Federal.

5 Com base em Bekin (2006)

Figura 2 - diretrizes em palavras-chave

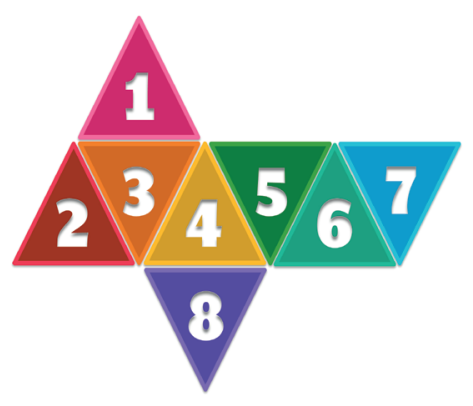

Fonte: Do Autor
1 CONSOLIDAR conceitos de Endomarketing: funcionário é cliente interno.

IMPLEMENTAR o Planejamento Estratégico da academia: missão, visão, valores e metas.

DEFINIR responsáveis pela gestão da Comunicação Interna e do Endomarketing.

ALINHAR as metas da Gestão de Pessoas (RH) com as do Endomarketing;

OFERECER sistematicamente programas de de incentivo ao cliente interno.

CONSOLIDAR os processo $\mathrm{e}$ os canais $\mathrm{d}$ Comunicação Interna e Endomarketing. CULTIVAR o hábito do feedback e divulgar sistematicamente os resultados para o cliente interno.

realizar sistematicamente Pesquisa de Clima Organizacional na academia.

Na imagem em forma de octaedro plano, enumeradas de um a oito, estão elencadas as diretrizes para orientar, de maneira geral, os programas de endomarketing:

1. Consolidar conceitos fundamentais de endomarketing: funcionários e colaboradores são clientes internos e devem ter identificadas suas necessidades e motivações específicas;

2. Implementar o planejamento estratégico da academia: devidamente definidos e divulgados missão, visão, valores e metas, maiores serão as chances de adesão dos colaboradores aos objetivos organizacionais;

3. Definir responsáveis pela gestão da comunicação interna e endomarketing da academia, a fim de que eles acompanhem indicadores que comprovem o progresso das ações;

4. Alinhar as metas da gestão de pessoas com as metas do endomarketing, de forma que o trabalho faça parte de uma gestão compartilhada por todos;

5. Oferecer sistematicamente programas de incentivo ao cliente interno para estimular o diálogo produtivo e a motivação;

6. Consolidar os processos e os canais de comunicação interna e endomarketing, considerando as características individuais e as atividades exercidas por cada colaborador;

7. Cultivar o hábito do feedback com o cliente interno e divulgar seus resultados obtidos, de forma a manter uma gestão transparente;

8. Realizar sistematicamente pesquisa de clima organizacional na academia para identificar e instituir ações preventivas e/ou corretivas.

As oito diretrizes não são exaustivas, mas poderão 
inspirar os programas de endomarketing nas academias esportivas do Distrito Federal. Para sua melhor eficácia, elas devem ser consideradas durante o processo de planejamento estratégico, tanto pela gerência da empresa, quanto pelos demais departamentos e áreas.

\section{Considerações finais}

De acordo com o presente estudo de caso realizado nas duas academias esportivas localizadas no Distrito Federal, constatou-se que estas conhecem apenas superficialmente as vantagens da gestão estratégica de marketing e de endomarketing (Gráfico 8), assim como entenderam os autores Toscano (2001) e Paula (1999).

Com base nas informações apresentadas, constatamos que a noção de marketing, no que se limita apenas ao cliente externo e à gestão de pessoas, é alheia a esses objetivos (Quadro 4). Esses são pontos frágeis dessas empresas, visto a ausência de políticas internas formais de endomarketing.

Para Mendes (2010) e Espirito-Santo e Mourão (2006), os profissionais que trabalham em academias convivem com situações exploradoras de mão de obra, e sua permanência nessas empresas se dá pelo fato de gostarem do que fazem (Gráfico 7 e Quadro 3).

Coincidiram também as respostas do Gráfico 6 e do Quadro 2 com os referidos autores quanto ao fato do acúmulo de funções, cargos e atribuições contribuir para a desmotivação de profissional. Isso porque tais exigências nem sempre são acompanhadas por remunerações proporcionais, além do que pode ser prejudicial à qualidade de vida e a saúde do trabalhador (ESPIRITO-SANTO; MOURÃO, 2006). Ou seja, o estudo de caso confirmou alguns pontos teóricos dissertados no referencial bibliográfico.

De acordo com o Quadro 4, os gestores exaltam prioritariamente fatores que atingem apenas o cliente externo, tais como estrutura física, estética das instalações e marketing externo. Dessa forma, aliado ao desconhecimento conceitual visível pelo Gráfico 8 , pode-se concluir que as instituições estudadas não consideram que a gestão estratégica de endomarketing suscita maior vantagem competitiva no mercado, pois não apreciam sua importância, destarte não exploram consciente e sistematicamente as ferramentas disponíveis.

Com base nesta pesquisa, foi possível elaborar oito diretrizes gerais que podem ser úteis quando da instau- ração de programas de endomarketing em academias de pequeno porte, na capital. Embora essas diretrizes não sejam exaustivas, elas podem abrir caminhos para referenciar novas pesquisas acadêmicas, contribuindo com as técnicas existentes ou até mesmo criação de novas.

\section{Referências}

ADORNO, Theodor W. Indústria cultural e sociedade. 5. ed. São Paulo: Paz e Terra, 2009.

ALVES, Fabiana Letícia Pereira et al. Endomarketing como ferramenta de estratégia empresarial. In: ENCONTRO NACIONAL DE ENGENHARIA DE PRODUÇÃO, 22., 2002, Curitiba. Anais eletrônicos... Curitiba: ABEPRO, 2002. Disponível em: <http://www.abepro.org.br/ biblioteca/ENEGEP2002_TR75_0651.pdf>. Acesso em: 20 jun. 2014.

ANTUNES, Hanna Karen M. et al. Alterações Cognitivas em idosas decorrentes do exercício físico sistematizado. Revista da Sobama, São Paulo, v. 6, n. 1, p. 27-33, dez. 2001. Disponível em: <http://www.cepebr.org/PDF/artigos/63.pdf >. Acesso em: 18 jun. 2014.

AZEVEDO JUNIOR, Mario Renato; ARAÚJO, Cora Luiza Pavin; PEREIRA, Flávio Medeiros. Atividades físicas e esportivas na adolescência: mudanças de preferências ao longo das últimas décadas. Revista Brasileira de Educação Física e Esporte, São Paulo, v. 20, n. 1, p. 51-58, jan./mar. 2006.

BARBANTI, Valdir. J. Dicionário de educação física e do esporte. São Paulo: Manole, 1994.

BARBOZA, Ana Paula; FERNANDES, Fernanda Soares; SILVA, Jéssica Fernandes da. A beleza feminina pela ótica da televisão e das revistas de moda. 2011. f. Monografia (Bacharel em Comunicação) - Faculdade de Ciências Sociais e Tecnológicas, Brasília, 2011.

BEKIN, Saul Faingaus. Endomarketing: como praticá-lo com sucesso. São Paulo: Pearson, 2006.

BROWNELL, K. D. Manejamento de peso e composição corporal. In: AMERICAN COLLEGE OF SPORTS MEDICINE. Prova de esforço e prescrição de exercício. Rio de Janeiro: Revinter, 1994. p. 352-358.

BRUM, Analisa de Medeiros. Endomarketing de A a Z: como alinhar o pensamento das pessoas à estratégia da empresa. São Paulo: Integrare, 2010.

BRUM, Analisa de Medeiros. Endomarketing como estratégia de gestão: encante seu cliente interno. Porto Alegre: L\&PM, 1998.

CHIAVENATO, Idalberto. Gestão de pessoas: o novo pa- 
pel dos recursos humanos nas organizações. 3. ed. Rio de Janeiro: Campus, 2004.

COBRA, Marcos Henrique Nogueira. Administração de marketing no Brasil. 3. ed. Rio de Janeiro: Elsevier, 2009. Disponívelem: $<$ http://books.google.com.br/books?hl=p$\mathrm{t}-\mathrm{BRelr}=\mathrm{eid}=\mathrm{lC} 6 \mathrm{WmnO}=-4 \mathrm{VkCeoi}=$ fndepg $=\mathrm{P} 11 \mathrm{Redq}-$ os+profissionais $+\mathrm{de}+$ neg $\% \mathrm{C} 3 \% \mathrm{~B} 3$ cios + adotam $+\mathrm{o}+$ ponto+de+vista+do+consumidor.+E+essas+decis\%C3\%B5$\mathrm{es}+\mathrm{s} \% \mathrm{C} 3 \% \mathrm{~A} 3 \mathrm{o}+$ tomadas $+\mathrm{com}+\mathrm{base}+$ no+que $+\mathrm{o}+-$ cliente + necessita $+e+$ desejaeots $=$ Pvv400TK0hesi -

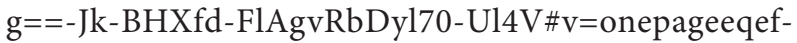
false>. Acesso em: 8 abr. 2014.

COBRA, Marcos Henrique Nogueira. Administração de marketing. São Paulo: Atlas, 1986.

COELHO FILHO, Carlos Alberto de Andrade. O discurso do profissional de ginástica em academia no Rio de Janeiro. Movimento: Revista da Escola de Educação Física da UFRGS, Porto Alegre, v. 6, n. 12, p. 14-25, jan./jun. 2000. Disponível em: <http://www.seer.ufrgs.br/movimento/article/download/2496/1140>. Acesso em: 24 abr. 2014.

CONTE, Marcelo et al. Influência da massa corporal sobre a aptidão física em adolescentes: estudo a partir de escolares do ensino fundamental e médio de Sorocaba/ SP. Revista Brasileira de Medicina do Esporte, Campinas, v. 6, n. 2, p. 44-49, mar./abr. 2000. Disponível em: <http:// www.scielo.br/pdf/rbme/v6n2/v6n2a03.pdf >. Acesso em: 10 mar. 2014.

CORBIN, Charles B.; LINDSEY Ruth. Concepts of physical fitness. California: Brown-Benchmark, 1997.

ESPÍRITO-SANTO, Giannina do; MOURÃO, Ludmila. A auto-representação da saúde dos professores de educação física de academias. Revista Brasileira de Ciências do Esporte, Porto Alegre, v. 27, n. 3, p. 39-55, maio 2006. Disponível em: <http://www.esporte.gov.br/arquivos/sndel/esporteLazer/cbce273.pdf>. Acesso em: 4 abr. 2014.

ESTEVÃO, Adriana; BAGRICHEVSKY, Marcos. Cultura da corpolatria e body-building: notas para reflexão. Revista Mackenzie de Educação Física e Esporte, São Paulo, v. 3, n. 3, p. 13-25, 2004. Disponível em: <http://editorarevistas.mackenzie.br/index.php/remef/article/view/1309>. Acesso em: 24 abr. 2014.

GRAZIANO, Graziela Oste. Marketing de relacionamento: a fidelização de clientes e o endomarketing na indústria de produtos orgânicos. 2011. f. Tese (Doutorado) Universidade Nove de Julho, São Paulo, 2011.

GRÖNROOS, Christian. Marketing: gerenciamento e serviços: a competição por serviços na hora da verdade. Rio de Janeiro: Campus, 1995.
IBGE. Evolução da Mortalidade 2000: Brasil. [2001] Disponível em: <http://www.ibge.gov.br/home/estatistica/populacao/tabuadevida/evolucao_da_mortalidade. shtm>. Acesso em: 18 jun. 2014.

IBGE. Teen Noticias. 2012. Disponível em: <http://teen. ibge.gov.br/noticias-teen>. Acesso em: 18 jun. 2014.

INKOTTE, Alexandre Luz. Endomarketing: elementos para a construção de um marco teórico. 2000. 144 f. Dissertação (Mestrado) - Programa de Pós-Graduação em Engenharia de Produção, Universidade Federal de Santa Catarina, Florianópolis, 2000. Disponível em: <http://endomarketing. com/wp-content/uploads/2014/10/publicacao-tese-alexandre-luz-inkotte.pdf>. Acesso em: 27 jul. 2014.

KOTLER, Philip; ARMSTRONG, Gary. Princípios de marketing. São Paulo: Pearson Prentice Hall, 2007.

LAS CASAS, Alexandre Luzzi. Administração de marketing: conceitos, planejamento e aplicações à realidade brasileira. São Paulo: Atlas, 2006.

LAVILLE, Christian; DIONNE, Jean. A construção do saber. Minas Gerais: Artmed, 2008.

MAIA, Flávia. DF é a unidade da Federação com maior número de academias: número é de um estabelecimento para cada 4,7 mil brasilienses. Correio Braziliense, Brasília, 14 set. 2014. Disponível em: <http://www.correiobraziliense.com.br/app/noticia/cidades/2014/09/14/interna_cidadesdf,446977/df-e-a-unidade-da-federacao-com-maior-numero-de-academias.shtml>. Acesso em: 20 set. 2014.

MENDES, Alessandra Dias. Atuação profissional e condições de trabalho do educador físico em academias de atividades físicas. 2010. 235 f. Dissertação (Mestrado) - Programa de Pós-Graduação, Faculdade em Educação Física, Universidade de Brasília, Brasília, 2010. Disponível em: <http://repositorio.unb.br/bitstream/10482/8095/1/2010_AlessandraDiasMendes.pdf $>$. Acesso em: 9 abr. 2014.

MENEGUELlO, Cristina. Poeira de estrelas: o cinema hollywoodiano na mídia brasileira das décadas de 40 e 50. Campinas: Unicamp, 1996.

MOCSÁNYI, Vinícius; BASTOS, Flávia da Cunha. Gestão de pessoas na administração esportiva: considerações sobre os principais processos. Revista Mackenzie de Educação Física e Esporte, São Paulo, v. 4, n. 4, p. 55-69, 2005.

PAULA, Gil de. Fitness business: administrando com resultados. Rio de Janeiro: Sprint, 1999.

PESTANA, Simery Conceição Constancio. Pesquisa de clima organizacional. 2001. 50 f. Monografia (Especialização lato sensu) - Universidade Cândido Mendes, Rio de Janeiro, 2001. 
REQUENA, Ivan Bim. Endomarketing: elas, as pessoas. Gestão Revista Científica de Administração, Curitiba, v. 1, n. 1, p. 7-51, jun./set. 2003. Disponível em: <http:// www.faculdadeexpoente.com.br/upload/noticiasarquivos/1204057594.PDF\#page=25 > . Acesso em: 17 jul. 2014.

RIBEIRO, Érica. Setor de fitness e mercado de academias movimentam mais de R\$ 2 bilhões no país: Brasil lidera setor em toda a América do Sul e é o segundo maior do mundo. IG, 27 jun. 2013. Economia: Comércios e Serviços. Disponível em: <http://economia.ig.com.br/ empresas/comercioservicos/2013-06-27/setor-de-fitness-e-mercado-de-academias-movimentam-mais-de-r-2-bilhoes-no-pais.html>. Acesso em: 22 jul. 2014.

RODRIGUES, Gizella. Brasil caminha para assumir liderança mundial em número de academias: levantamento do SEBRAE mostra que, em três anos, o número de empreendimentos cresceu 29\%. Agência SEBRAE de Notícias, 26 ago. 2014. Disponível em: <http://www.agenciasebrae.com.br/sites/asn/uf/NA/Brasil-caminha-para-assumir-lideran\%C3\%A7a-mundial-em-n\%C3\%BAmero-de-academias>. Acesso em: 20 set. 2014.

SABA, Fabio. A importância da atividade física para a sociedade e o surgimento das academias de ginástica. Revista Brasileira de Atividade Física e Saúde, Pelotas, v. 3, n. 2, p. 80-87, maio/jun. 2012. Disponível em: <http:// periodicos.ufpel.edu.br/ojs2/index.php/RBAFS/article/ view/1085>. Acesso em: 28 abr. 2014.
SEBRAE. Boletim: moda fitness. 2014a Disponível em: $<$ www.sebrae2014.com.br/Sebrae/Sebrae\%202014/Boletins/2014_08_04_BO_Maio_Moda_ModaFitness_pdf. pdf>. Acesso em: 15 abr. 2015

SEBRAE. Critérios e conceitos para classificação de empresas: saiba como classificar empresas por porte. $2014 \mathrm{~b}$ Disponível em: <http://arquivopdf.sebrae.com.br/uf/goias/ indicadores-das-mpe/classificacao-empresarial $>$. Acesso em: 20 set. 2014

SUDO, Nara; LUZ, Madel. O gordo em pauta: representações do ser gordo em revistas semanais. Revista Ciência e Saúde Coletiva, Rio de Janeiro: v. 12, n. 4, p. 1033-1040, jul./ago. 2007. Disponível em: <http://www.scielosp.org/ pdf/csc/v12n4/21.pdf>. Acesso em: 30 mar. 2014.

TOSCANO, José J. de O. Academia de ginástica: um serviço de saúde latente. Revista Brasileira de Ciência e Movimento, Brasília, v. 9, n. 1, p. 40-42, jan. 2001. Disponível em: <http://portalrevistas.ucb.br/index.php/RBCM/article/viewArticle/381>. Acesso em: 19 jul. 2014.

VIGARELLO, Georges. A história da beleza: o corpo e a arte de se embelezar do renascimento aos dias de hoje. Rio de Janeiro: Ediouro, 2006.

YIN, Robert K. Estudo de caso: planejamento e métodos. Porto Alegre: Bookman, 2001. 